\title{
First look at the Five-Factor Model Personality Facet Associations with Sensory Processing Sensitivity
}

\section{Published in Current Psychology}

$\underline{\text { Anne Sophie Broehl }}^{\mathrm{a}}$, Karla Van Leeuwen ${ }^{\mathrm{b}}$, Michael Pluess ${ }^{\mathrm{c}}$, Filip De Fruyt ${ }^{\mathrm{d}}$, Margot Bastin ${ }^{\mathrm{a}}$, Sofie Weyn ${ }^{\mathrm{a}}$, Luc Goossens ${ }^{\mathrm{a}}$, Patricia Bijttebier ${ }^{\mathrm{a}}$

${ }^{a}$ KU Leuven, School Psychology and Development in Context, Tiensestraat 102, Leuven, 3000, Belgium

${ }^{\mathrm{b}}$ KU Leuven, Parenting and Special Education, Vanderkelenstraat 32, Leuven, 3000, Belgium ${ }^{\mathrm{c}}$ Queen Mary University of London, School of Biological and Chemical Science, Mile End Road, London, E1 4NS, United Kingdom

${ }^{\mathrm{d}}$ Ghent University, Developmental, Personality and Social Psychology, Henri Dunantlaan 2, 9000, Ghent, Belgium

Corresponding Author:

Anne Sophie Bröhl

School Psychology and Development in Context Faculty of Psychology and Educational Science KU Leuven

Tiensestraat 102, Leuven, 3000, Belgium

annesophie.broehl@kuleuven.be, +3216322503 


\begin{abstract}
The current paper presents an examination of the associations between Five-Factor Model (FFM) personality facets and Sensory Processing Sensitivity (SPS) to understand which personality facets are especially relevant for SPS. Associations between SPS and the FFM personality domains and facets were examined in older adolescents and young adults (Study 1) as well as older children and young adolescents (Study 2). The most relevant facets were within the Neuroticism and Openness domains, although not all facets were equally important. Especially facets regarding internalizing tendencies and - in older adolescents and young adults - openness to aesthetics showed highest association with SPS. Facets of Extraversion were less associated to SPS. Facets of domains Agreeableness and Conscientiousness showed almost no relevance to SPS.
\end{abstract}

Keywords: sensory processing sensitivity, five-factor model, personality, child/adolescent, young adult. 
Environmental sensitivity has been defined as the ability to perceive and process external stimuli (Pluess, 2015). Although important for every individual, some people appear to be more sensitive to environmental exposure than others; for instance, being bothered by light, sounds, or smells more quickly than others (e.g., Aron \& Aron, 1997). Researchers have tried to understand such individual differences in reactivity to the environment in terms of both physiological mechanisms (e.g., heightened stress reactivity; Boyce \& Ellis, 2005) and phenotypic manifestations (e.g., temperamental reactivity; Aron, Aron, \& Jagiellowicz, 2012). Sensory Processing Sensitivity (SPS) has been put forward as trait manifestation of environmental sensitivity (Aron \& Aron, 1997; Pluess, 2015).

The aim of this paper is to relate SPS to the Five-Factor Model of personality, with a special focus on its facets. We will attempt to do this with two community samples of lateadolescents to young adults (Study 1), and children to early adolescents (Study 2). We will conduct canonical correlation analyses between the adult measure of SPS and an adult FFM measure (Study 1), as well as between the child measure of SPS and a child measure of the FFM (Study 2). Conducting the analyses across two different age groups will allow us to begin to understand potential developmental differences in SPS.

\section{Sensory Processing Sensitivity (SPS)}

According to Aron and Aron (1997) SPS incorporates a combination of greater awareness of subtleties and deeper information processing, as well as increased emotionality and empathy, ease of overstimulation, and sensitivity to bodily stimuli like hunger or pain. In addition, individuals high in SPS would be more susceptible to both positive and negative environments (for a full review, see Greven et al., 2019). For example, a highly sensitive person can be more vulnerable to stress, but also more captivated by music and art. So far, SPS has been measured with the Highly Sensitive Person scale (HSP, Aron \& Aron, 1997) and more recently the Highly Sensitive Child scale (HSC, Pluess et al., 2018). Aron and Aron 
(1997) assumed SPS to be unidimensional and provided factor analytic evidence for a onefactor model of the HSP, but later factor analytic studies suggested a three-factor model, arranging the HSP scale into three subdomains comprising Ease of Excitation (EOE), Low Sensory Threshold (LST), and Aesthetic Sensitivity (AES; Smolewska, McCabe, \& Woody, 2006), as well as a bi-factor structure representing SPS both in terms of the total scale and its subscales (Lionetti et al., 2018). A similar structure was found for the HSC scale (Pluess et al., 2018, Weyn et al., 2019). The EOE subscale includes items that refer to being affected by external and internal stimuli, the LST subscale refers to overstimulation by sensory input, whereas the AES subscale contains items that mainly refer to processing of aesthetic stimuli and depth of perception (Smolewska et al., 2006). The bi-factor model suggests that in order to understand SPS it is worth to consider both the total scale, as well as its subdomains. However, the subdomains were established later on and are thus not based on theory (Pluess et al., 2018; Weyn et al., 2019).

\section{Five-Factor Model (FFM) of Personality}

In five domains, each domain having multiple facets, the FFM of personality allows for a broad assessment of individual differences in personality (for detailed review, see Goldberg, 1993). Several approaches have been used within research on the FFM that yielded slightly different conceptualizations of the domains in terms of the facets they consist of (Goldberg, 1993; John, 1990). For the current article we will use models based on the factor structure proposed by McCrae and Costa (1987), as well as based on the parental free descriptions of personality of children (Kohnstamm, Halverson, Mervielde, \& Havill, 1998). Both approaches structure personality in five domains (i.e., McCrae \& Costa, 1987: Neuroticism, Extraversion, Openness to Experience, Agreeableness, Conscientiousness; Kohnstamm et al., 1998: Emotional Stability, Extraversion, Imagination, Benevolence, 
Conscientiousness). However, the domains differ in terms of the facets they are composed of. For a detailed overview of the facets see Table 1 and Table 2.

SPS has been related to personality in previous studies. In their recent meta-analysis, Lionetti and colleagues (2019) investigated associations between the Five-Factor Model (FFM) of personality and SPS. Investigations were conducted on a domain level of the FFM and SPS as a whole as well as its subdomains, in both child and adult samples. Across different FFM measures, the authors found a moderate association between the Neuroticism domain and SPS in both children and adults; the Openness to Experience domain was weakly correlated with SPS, but only in adults, there was no association in children; Extraversion, Agreeableness and Conscientiousness showed no association in both children and adults (Lionetti et al., 2019). A case for Extraversion made a study by Şengül-İnal, Kirimer-Aydinli, and Sümer (2018). The authors reported a small but consistent negative association between Extraversion and SPS, as well as a mediator between behavioral inhibition/activation systems and SPS. On SPS subdomain level Lionetti and colleagues (2019) reported that Neuroticism was positively associated with EOE and LST, in both adults and children and somewhat less strong with AES in adults. Openness to Experience was associated to AES in both adults and children, though to a somewhat lesser extent in the latter age group (Lionetti et al., 2019). They suggested, because of - at best - only moderate associations between the FFM domains and SPS total scale as well as its subdomains, that SPS is a distinctive trait, rather than a trait within the FFM (Lionetti et al., 2019).

An important limitation of earlier research is that the association between SPS and the FFM of personality has been examined only at the domain level of personality (see Greven et al., 2019; Lionetti et al., 2019). We will attempt to understand this association further by looking at associations at the facet level, in adolescents and young adults. This approach can give us a more detailed understanding of the different facets of personality that compose SPS. 
We hypothesize that SPS is a blend of personality facets across domains, and that - even within domains - some facets will be more important for understanding SPS than other. Based on the meta-analysis (Lionetti et al., 2019) and recent findings by Şengül-İnal and colleagues (2018) we hypothesize that

a) The most relevant facets will be part of the Neuroticism domain, and - to somewhat lesser extent - Openness to Experience (especially related to the AES aspect of SPS).

b) Facets of Extraversion will be marginally associated with SPS.

c) Facets of Agreeableness and Conscientiousness will be of less, if any, importance.

We will investigate this in two studies with samples of different age groups using selfrated personality and SPS questionnaires. 


\section{Study 1}

\section{Method}

\section{Participants and Procedure}

The sample of Study 1 consisted of 397 older adolescents and young adults $(64.5 \%$ female) with a mean age of 19.70 years ( $\mathrm{SD}=2.84$ years, range 16.17 to 26.08 years), $88.9 \%$ reported to be in education. The study was performed in line with the principles of the Declaration of Helsinki and in line with the ethical standards of the KU Leuven at the time of the data collection. Participants were recruited from three schools in Grades 11 and 12, as well as from the researchers' network through the snowball method. Several schools were contacted in the Dutch speaking part of Belgium. After consent of the school director, parents were asked to give their passive consent. Furthermore, active informed consent was obtained from all participants before participation. Participants recruited in schools were asked to fill out the questionnaires in collective sessions during school hours. Participants from the network (acquaintances, sport and youth clubs) were given the questionnaires to be filled out at home and sent back to the researchers. Of the 432 recruited participants, we excluded 35 participants because of more than $10 \%$ missing data, which was considered the cut-off. In addition, only around $8 \%$ of the cases in this sample had missing data. As the amount of data is less than $10 \%$, we decided to delete the cases rather than considering imputations (Bennett, 2001).

\section{Measures}

Personality. Participants were asked to fill out the NEO-PI-3 (McCrae, McCrae, Costa, \& Martin, 2005; Dutch translation by Hoekstra \& De Fruyt, 2014), which is a FFM of personality questionnaire with 240 items, five domains (Neuroticism, sample $\alpha=.92$; Extraversion, sample $\alpha=.90$; Openness to Experience, sample $\alpha=.89$; Conscientiousness, sample $\alpha=.92$; Agreeableness, sample $\alpha=.90$ ), six facets (all sample $\alpha>.56$ ) per domain 
and eight items per facet. Statements were rated on a 5-point Likert scale from 1 (strongly disagree) to 5 (strongly agree) (see Table 1 for a description of the facets). Although being generally for adults, this measure has been successfully used with an adolescent sample before (e.g., De Fruyt, Mervielde, Hoekstra, \& Rolland, 2000).

\#\#\#\#\#

TABLE 1 about here

\#\#\#\#\#

Sensory Processing Sensitivity (SPS). The 12-item short version (Pluess, Lionetti, Aron, \& Aron, in preparation, see Appendix 1 for items) of the HSP questionnaire (sample total scale $\alpha=.74$ ) by Aron and Aron (1997) consists of three subscales: Ease of Excitation (EOE, 5 items, sample $\alpha=.73$ ), Low Sensory Threshold (LST, 3 items, sample $\alpha=.59$ ), Aesthetic Sensitivity (AES, 4 items, sample $\alpha=.72$ ). Statements were rated on a 7-point Likert scale from 1 (not at all) to 7 (extremely). For this study the Dutch translation by Bijttebier, Weyn, Goossens, Bastin, and Van Hoof (Aron \& Aron, 2014) was used. The scale was translated with a translation-back translation approach, which was approved by experts in the field. The psychometric properties of the translated HSP scale were tested with the current sample. The mean score of the total scale was $3.99(S D=.80)$. The mean scores of the three subscales were $4.43(S D=1.00)$ for EOE, $3.30(S D=1.22)$ for $\mathrm{LST}$, and $4.26(S D=1.12)$ for AES. Confirmatory Factor analyses revealed that the items of the HSP scale fit a bi-factor model, reflecting both a general sensitivity factor and three sensitivity component: EOE, LST, and AES. The bi-factor model showed a good model fit $\left(\chi^{2}(42)=70.613, p=.004\right.$; RMSEA $=.04 ; \mathrm{CFI}=.97 ; \mathrm{SRMR}=.05)$. 


\section{Data Analysis}

A canonical correlation analysis was conducted to capture latent associations between the two sets of variables. We will follow interpretation as suggested by Sherry and Henson (2010): we consider an effect size of $r_{\mathrm{s}}>.45$ as relevant for the functions. In order to detect at least a correlation coefficient of .20 between FFM facets and SPS with a significant result $(p<0.05)$ and a sufficient power (80\%), the minimum required sample size for this study is 258 (based on Guenther, 1977). A correlation coefficient of .20 was selected because correlations from .45 onwards become most relevant for this study, as it is considered sizable (Sherry \& Henson, 2010).

Correlations were computed to test the hypotheses, more specifically: canonical correlation between the facet level scores and the HSP subscale scores. Although taking the correlations at the facet/subscale level, the canonical correlation analysis allows to consider personality domains and the overall HSP scale as well. Please note, that although personality facets are treated as predictors, they are not interpreted as such, as we are mainly interested in the correlation and variance between the two sets of variables.

As additional analyses we ran canonical correlation analyses for male and female participants separately, to start to understand potential gender differences. 


\section{Results}

\section{Canonical Correlation Analysis}

A canonical correlation analysis was conducted with the 30 NEO-PI-3 personality facets treated as predictors of the three HSP subscales EOE, LST, and AES to investigate the multivariate shared relationship between the two sets of variables (personality and high sensitivity). The analysis yielded 3 functions with squared canonical correlations $\left(R_{\mathrm{c}}{ }^{2}\right)$ of .58 (Function 1), .50 (Function 2), and .17 (Function 3), which represent the shared variance explained between the synthetic functions of the two sets of variables. The full model across all functions accounted for $82.36 \%$ of the shared variance (Wilk's $\lambda=.18, p<.001$ ). The dimension reduction analysis showed all hierarchal arrangement of functions were significant, i.e., the full model $(F(90,1090.20)=9.52, p<0.001)$, Functions 2 to $3(F(58,730)=6.90, p$ $<0.001)$, as well as Function $3(F(28,366)=2.63, p<0.001)$.

All functions were considered noteworthy because of their $R_{\mathrm{c}}{ }^{2}$ effects sizes. The standardized canonical function coefficients, (squared) structure coefficients, as well as their communalities $\left(h^{2}\right)$ for Functions 1 to 3 can be found in Table 3. Looking at the coefficients of Function 1, the relevant criterion variables were facets Aesthetics and Ideas making primary, and facets Fantasy, Actions and Values making secondary contributions to the synthetic criterion variable. This was supported by the squared structure coefficient $\left(r_{s}^{2}>.40\right.$ for primary contribution, $r_{s}{ }^{2}=.20$ for secondary contribution). The facet Aesthetics had a larger canonical function coefficient, compared to Ideas and the other mentioned facets. All the aforementioned facets had the same positive sign, indicating that they were positively related with each other. The AES subscale was the primary contributor to the predictor synthetic variable. The AES structure coefficient was positive - like the mentioned facets of openness to experience - indicating a positive correlation between the two, which is in line with our expectations. The EOE and LST subscales did not contribute much to the synthetic 
variable, indicating that facets of Openness cannot explain high sensitivity as a whole. So we turn to Function 2.

The second function, which was able to explained about $50 \%$ percent of the remaining common variance in the variable sets, had contributions primarily from facets Anxiety, Vulnerability, Depression, and Self-Consciousness (from Neuroticism), with $r_{s}^{2}>.35$, and secondarily from Aesthetics (from Openness to Experience), with $r_{s}^{2}=.20$. Facets Anxiety, Vulnerability and Aesthetics had larger canonical function coefficients, compared to facets Depression and Self-Consciousness, which were rather small. All facets mentioned from Neuroticism were positively correlated with each other, as well as with Aesthetics. The EOE subscale was the largest contributor to the predictor synthetic variable, but also the LST scale contributed to the function. The relevant facets of Neuroticism and Aesthetics were positively correlated with EOE and LST.

The third function did not have as large contributions as the first two functions, with Deliberation, Excitement-Seeking and Self-Discipline being the major contributors of this function with $r_{s}^{2}>$.18. Excitement-Seeking was negatively related with Deliberation and Discipline. The LST subscale was the largest contributor to the predictor function and was negatively correlated with Excitement-Seeking and positively correlated with Deliberation and Self-Discipline. It should be noted that the functions could only explain $17 \%$ of the remaining variance, so interpretation should be done with caution.

Looking at gender, we could not find many differences. The coefficient tables can be viewed in the supplementary material. For both women and men, the first two functions were most relevant (for men, the third function was not significant; for women, the third function did not yield substantial coefficients, i.e. all $\left.r_{s}<.45\right)$. The first functions of both genders had primary contributions by Aesthetics and Ideas, and secondary contributions by Feelings and 
Fantasy as well as Values for men and Action for women, with AES as primary contributor to the first function of Sensory Processing Sensitivity. The second function for both genders had Anxiety and Vulnerability as primary contributor, as well as Depression for women.

Secondary contributions were made by Self-Consciousness, as well as Depression for men, and Gregariousness and Aesthetics for women. For SPS, the primary contributor were EOE and LST for both genders, as well as AES for women.

\section{\#\#\#\#\#}

TABLE 3 about here

\#\#\#\#\#

\section{Discussion}

The purpose of this study was to understand the specific associations between the HSP scale and the facets of FFM. Conducting a canonical correlation analysis helped to do so. We hypothesized that facets of Neuroticism and Openness to Experience were most important for the connection to SPS. We found evidence in support of that hypothesis. However facets of Openness to Experience contributed more to the shared connection than Neuroticism, which was somewhat unexpected. Facets of Extraversion only marginally contributed in the adult sample. Facets of Agreeableness and Conscientiousness were of no importance.

The first function showed a strong connection of AES with the facets of Openness to Experience, especially with Aesthetics, Ideas and Fantasy. That is, individuals scoring high on aesthetic sensitivity, scored high in enjoyment of, fascination by, and interest in music and art (Aesthetics); high in the affinity to philosophical and abstract theories, ideas, and discussions, eagerness to learn and intellectual interest (Ideas); and scored high on imagination and an affinity for daydreaming (Fantasy). These facets were strongly related to the aesthetic sensitivity aspect of SPS, i.e., participants high in aesthetic sensitivity seemed to 
be appreciating and engaging in culture. The secondary contributors Feelings (strong emotions and the appreciation and recognition of them, as well as empathy) and Values (tolerance for other cultures and believes) suit this description as well.

The second synthetic variable set (Function 2) on the other hand showed the internalizing facets of Neuroticism (i.e., Anxiety, Depression, Vulnerability, and SelfConsciousness) to be strongly positively related with EOE and, albeit less, LST. The two facets that are more closely linked to externalizing tendencies (i.e., Angry Hostility and especially Impulsiveness) were less related to the HSP scale. Interestingly, Aesthetics also contributed positively to the function. That is, part of the variance that could not be explained by Function 1, which had the strongest contribution by the AES subscale, could be explained with the second function that had its strongest contribution by the EOE and LST subscales. Thus, affinity to and fascination by music and art is present for individuals scoring high on all three subscales.

Furthermore, it is noteworthy that for the second function both EOE and LST subscales contribute to the predictor synthetic variable. This seems to indicate that they are not as distinct from each other when explaining the variance in internalizing tendencies.

Turning to the third function, we saw that for the $17 \%$ accounted variance between the two synthetic functions, the main contributor were Excitement-Seeking (Extraversion), SelfDiscipline and Deliberation (both Conscientiousness). This function is the only function of the set to have a facet of Extraversion as contributor. Low Sensory Threshold (LST) has a negative correlation to Excitement-Seeking, that is the lower one's sensory threshold is, the less one is looking for excitement. For the two facets of conscientiousness, Self-Discipline and Deliberation, are positively correlated to LST, indicating that the higher one's sensory threshold, the higher one's self-discipline and deliberation. However, the explained variance 
is rather low for this function, which indicates that whereas SPS behavior might be confused with Introversion, this overall weak association adds to the evidence that SPS should be more distinguished from general introversion (Aron \& Aron, 1997; Smolewska et al., 2006). Furthermore, it suggests that conscientiousness is not very relevant for the SPS construct. However, in studying associations of SPS with outcomes, conscientiousness (as well as agreeableness, which did not have any notable contributions) might be interesting to consider as potential moderators.

Looking at the variance in each variable that was explained by the three functions (i.e., the communality coefficients), Anxiety, Depression, Vulnerability, Excitement-Seeking and Feelings appeared to be the most useful personality facets across the canonical solutions. For men, Anxiety and Aesthetics EOE and AES were especially important. For women the facets Anxiety, Depression, Vulnerability, Aesthetics, Feelings, and Ideas, were most useful. The gender differences were not the primary focus of this study, hence the sample sizes (of male/female) were not large enough to meet the power requirements, thus further research is necessary to investigate whether these gender differences are replicable. 


\section{Study 2}

\section{Method}

Participants and Procedure. Participants were 472 pupils (57\% female) recruited from five different schools in Grades 5 to 8 with a mean age of 12.26 years $(S D=1.19$ years, range 9.58 to 15.58 years). The study was performed in line with the principles of the Declaration of Helsinki and in line with the ethical standards of the KU Leuven at the time of the data collection. Several schools were contacted in the Dutch speaking part of Belgium. After consent from the school director, passive informed consent was obtained from parents. A total of 27 pupils did not receive permission from their parents to participate, which resulted in an analytical sample of 472 participants. Pupils who got permission to participate also provided informed consent. Participants filled out the questionnaires in collective sessions during school hours. Of the 477 recruited participants, we excluded 5 participants because of more than $10 \%$ missing data, which was considered the cut-off. In addition, only around $1 \%$ of the cases in this sample had missing data. As the amount of data is less than $10 \%$, we decided to delete the cases rather than considering imputations (Bennett, 2001).

\section{Measures.}

Personality. Participants filled out the Hierarchical Personality Inventory for Children (HiPIC, Mervielde, De Fruyt, \& De Clercq, 2009). This instrument is a parent-report and selfreport FFM of personality questionnaire with 144 items developed for children aged 6 to 12 . Here, the self-report version was used, as children were old enough to respond on their own (De Fruyt et al., 2000). The instrument was chosen because it was developed specifically for assessing children's personality traits within the FFM and thus suits their development stage. In addition, the HiPIC was found to be comparable with the Revised NEO Personality Inventory (Costa \& McCrae, 1992) an earlier version of the NEO-PI-3 (McCrae et al., 2005), in adolescents (De Fruyt et al., 2000). The HiPIC consists of five domain scales (Emotional 
Stability, sample $\alpha=.88$; Extraversion, sample $\alpha=.87$; Imagination, sample $\alpha=.81$;

Conscientiousness, sample $\alpha=.85$; Benevolence sample $\alpha=.87$ ), and a total of 18 facet scales (all sample $\alpha>.59$ ), with eight items per facet (see Table 2 for a description of the facets; Mervielde et al., 2009). Statements were self-rated on a 5-point Likert scale from 1 (strongly disagree) to 5 (strongly agree).

\#\#\#\#\#

TABLE 2 about here

\#\#\#\#\#

Sensory Processing Sensitivity (SPS). To assess SPS, participants filled out the 12item HSC scale (Pluess et al., 2018, Dutch translation by Weyn and colleagues (2019)). The HSC (sample $\alpha=.67$ ) is the child version of the HSP scale by Aron and Aron (1997). It contains the same three subscales: Ease of Excitation (EOE, 5 items, sample $\alpha=.69$ ), Low Sensory Threshold (LST, 3 items, sample $\alpha=.58$ ), Aesthetic Sensitivity (AES, 4 items, sample $\alpha=.50$; Pluess et al., 2018). Statements were rated on a 7-point Likert scale from 1 (not at all) to 7 (extremely). 
Data Analysis. Power calculations were the same as in Study 1. To test our hypotheses, the same analyses as in Study 1 were performed.

\section{Results}

Canonical correlation analysis. A canonical correlation analysis was conducted with the 18 HiPIC personality facets treated as predictors of the three HSC subscales EOE, LST, and AES to investigate the multivariate shared relationship between the two sets of variables (personality and high sensitivity). Please note, that like in Study 1 although personality facets are treated as predictors, they are not interpreted as such, as we are mainly interested in the correlation and variance between the two sets of variables. The analysis yielded 3 functions with squared canonical correlations $\left(R_{\mathrm{c}}{ }^{2}\right)$ of .43 (Function 1), .23 (Function 2), and .08 (Function 3), which represent the shared variance explained between the synthetic functions of the two sets of variables. The full model across all functions accounted for $59.78 \%$ of the shared variance (Wilk's $\lambda=.40, \mathrm{p}<.001$ ). The dimension reduction analysis showed all hierarchal arrangement of functions were significant, i.e., the full model $(F(54,1344.62)=$ 8.90, $p<0.001)$, Functions 2 to $3(F(34,904)=5.02, p<0.001)$, as well as Function $3(F(16$, $453)=2.42, p=0.002)$.

Functions 1 and 2 were considered noteworthy because of their $R_{\mathrm{c}}{ }^{2}$ effects sizes, thus the main interpretations will only include Functions 1 and 2. The standardized canonical function coefficients, (squared) structure coefficients, as well as their communalities $\left(h^{2}\right)$ for Functions 1 to 3 can be found in Table 4. Looking at the coefficients of Function 1, the relevant criterion variables were primarily facets Anxiety, Self-Confidence, Shyness, and secondarily Irritability and Perseverance. This was supported by the squared structure coefficient $\left(r_{s}^{2}>.40\right.$ for primary criterion variables, and $r_{s}^{2}>.25$ for secondary variables). The facets Anxiety, Self-Confidence, Shyness, and Perseverance also had a moderate canonical function coefficient, Irritability had a very small coefficient, which was due to 
multicollinearity with the other two functions. Anxiety, Shyness, and Irritability were positively related with each other, and negatively related with Self-Confidence and Perseverance.

The EOE and LST subscales were primary contributors to the predictor synthetic variable. Both EOE and LST structure coefficients were indicating a positive correlation between Anxiety, Shyness and Irritability, as well as a negative correlation with SelfConfidence and Perseverance.

The second function had contributions primarily from facets Curiosity and Expressiveness, with $r_{s}^{2}>.40$, and secondarily from Optimism, Creativity, and Energy, Intellect, and Altruism, with $r_{s}^{2}>.20$. Facets Curiosity, Expressiveness, Energy, Creativity and Intellect had a moderate canonical function coefficient. Optimism and Altruism had a small function coefficient, which was due to multicollinearity with other criterion variables. All facets mentioned were positively related with each other. The AES subscale was the largest contributor to the predictor synthetic variable and was positively correlated with the aforementioned facets.

There were small gender differences. Although both Function 1 and Function 2

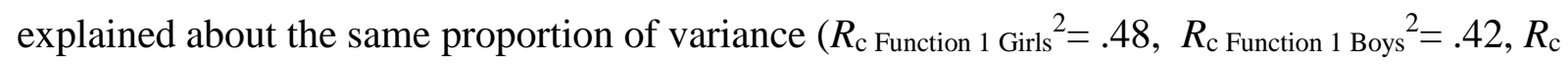
Function 2 Girls $^{2}=.27, R_{\mathrm{c}}$ Function 2 Boys $^{2}=.28$ ), their compositions were slightly different, especially for Function 1. Function 1, for both girls and boys, had contributions by the structure coefficients from Anxiety, Self-Confidence, Shyness, and Perseverance. In addition, girls had contributions from Optimism, Intellect, and Irritability, whereas Egocentrism contributed to the function for boys. The facets Energy, Expressiveness, Optimism, Intellect, and Curiosity contributed to Function 2 for both genders. Girls also had contributions from Altruism, whereas Creativity contributed to the second function for the boys. The third function was 
non-significant for boys (Wilk's $\lambda=.89, p=.11$ ), and only explained a small proportion of variance for girls $\left(R_{\mathrm{c}}^{2}=.10\right.$, Wilk's $\left.\lambda=.90, p=.03\right)$.

\#\#\#\#\#

TABLE 4 about here

\#\#\#\#\#

\section{Discussion}

In this sample of children and early adolescents, two functions were considered relevant for interpretation, due to the amount of variance explained. We hypothesized that facets of Neuroticism and Openness to Experience were most important for the connection to SPS. We found evidence in support of that hypothesis. In addition, facets of Neuroticism were more relevant to SPS than Openness to Experience, as expected. Facets of Extraversion contributed more to explaining the association between SPS and FFM than expected. Some facets of Agreeableness and Conscientiousness made some contributions as well.

The first synthetic variable set (Function 1) showed a strong correlation of both facets of Emotional Stability and Shyness (Extraversion) with the EOE and LST aspect of SPS. Both Anxiety and Self-Confidence refer to the propensity to internalizing behavior: Anxiety refers to worry, fear and panic, physiological responses to disappointment, and depressive symptoms; Self-Confidence refers to having less insecurities, and less self-doubt. The inhibition of behavior facet Shyness, suits well to the pair of facets. Inhibition and internalizing tendencies were shown to be a substantial part of SPS. Furthermore, Irritability and Perseverance were secondary contributors. Both facets fit thematically to ease of excitation and low sensory threshold. 
The second function displayed a strong relation between all facets of Imagination, all facets of Extraversion (but Shyness) and the AES aspect of SPS. The facet Curiosity, the strongest contributor to the second function, in the Imagination domain refers to the willingness to understand how things work and why. Aron and Aron (1997) based their sensory processing scale on the idea that sensitive individuals process information more in depth. Perhaps this ability to process information more deeply also affects one's preference for deeper understanding. Creativity contributed to the function as well, which refers to imagination and creative ideas. Intellect stands out in the Imagination domain, as its content is a bit atypical for a personality measure, covering - at least in part - self-reported intelligence (e.g., comprehension and verbal abilities).

The second strongest contributor, Expressiveness, refers to the tendency to convey thought and feelings. Optimism, comprises being joyful, cheerful, light-hearted, and careless. The facets of the Extraversion domain largely covers positive affect (i.e., the facets Optimism, Energy, and Expressiveness), and appeared to be positively related to the AES aspect of SPS. It thus appeared that highly sensitive children can possess aspects of extraversion. Altruism of the Benevolence domain contributed to the function as well, which refers to being empathetic and caring. It has to be addressed that the second function explained only $23 \%$ of the variance unexplained by the first function, thus associations of the facets of Imagination and the mentioned facets of Extraversion were less relevant to SPS than the mentioned associations of the first function.

Looking at the variance in each variable that was explained by the three functions (i.e., the communality coefficients), Anxiety, Self-Confidence, Optimism, Shyness and Curiosity are standing out as the most useful facets. For SPS, EOE and AES were most relevant. For girls, Anxiety, Self-Confidence and Optimism were the most useful facets. For boys, Anxiety, Self-Confidence, Shyness and Curiosity were most important. 


\section{General Discussion}

The purpose of this article was to gain better insight into the construct of Sensory Processing Sensitivity (SPS) by examining its latent associations with facets of the FFM. Through the analysis we were able to understand which facets of personality drive the associations with SPS and its subscales, and which facets are less important. We saw that high sensitivity seems to be represented in a combination of facets, which will be further discussed below.

Although both studies use a FFM measurement of personality, differences between instruments are to be considered, given that one measure was specifically developed for adults and the other for children and the two instruments follow a different approach. The NEO-PI-3 (McCrae et al., 2005) measure follows the FFM as developed by McCrae and Costa (1987) with the domains Neuroticism, Extraversion, Openness to Experience, Agreeableness, and Conscientiousness. The HiPIC measure by Mervielde and colleagues (2009) is based on a free description approach representing their content in the five dimensions Emotional Stability, Extraversion, Intellect, Benevolence, and Conscientiousness. All in all, both measures comprise comparable broad domains, which - in the remainder of this discussion section - we will label Neuroticism/Emotional Stability, Openness to Experience/Imagination, Extraversion, Agreeableness/Benevolence, and Conscientiousness. However, it is important to take into account that the composition of the domain scores as well as the content of the items comprising specific facets differs to a significant extent, which makes comparisons across the two measures less straightforward. Therefore, we do not simply adhere to the labels used but also look at the content of the items to clarify some of the findings.

Furthermore, we tried to understand the findings in terms of SPS as a global construct as well as its different aspects (i.e., EOE, LST, and AES), as suggested by Pluess and 
colleagues (2018) and Weyn and colleagues (2019). When referring to the subdomains, it is important to keep in mind that they were developed later on, while the original scale was conceived of as total scale.

\section{Neuroticism/Emotional Stability}

Across both studies, the strongest associations were those with facets referring to proneness to internalizing behavior. Individuals who were more sensitive seemed to be more inclined to feel anxious, self-conscious, and depressed. This finding is in line with Liss and colleagues (2005), who found that sensitivity can lead to a vulnerability for anxiety and depressive symptoms in non-clinical individuals. Emotional Stability in the HiPIC was more strongly related to sensitivity in the current study (evident by contributing to the first function), which might be due to the fact that Emotional Stability (HiPIC) does not comprise any facets related to anger proneness or impulsivity, i.e. externalizing behavior, unlike the NEO-PI-3 domain Neuroticism. As proneness to externalizing behavior appeared to be less related to SPS, the whole NEO-PI-3 domain becomes less associated with sensitivity. This example clearly illustrates how important it is to look at the facet level, and not just the domain level, to better understand SPS.

\section{Openness to Experience/Imagination}

Openness to Experience in the NEO-PI-3 and Imagination in the HiPIC have a quite different composition at the facet level. The NEO-PI-3 covers openness with a broad range of topics (e.g., fantasy, deep feelings, interest in and appreciation of aesthetics, as well as abstract and new ideas), whereas the HiPIC is more restricted and comprises facets such as intellect, which is at least in part perceived intelligence rather than openness. In their study about personality development in adolescents Allik, Laidra, Realo and Pullmann (2004) suggest that Openness to Experience increases in the course of adolescence. Comparing the 
two functions that had contributions by facets of Openness to Experience/Imagination, Allik and colleagues (2004) suggestions might explain the substantial difference in variance explained between the functions. The HiPIC was tailored to children, thus a lack of comparable Openness items might be a consequence of the fact that Openness to Experience has yet to develop.

However, there are some similarities, as both comprise aspects of the affinity towards art and knowledge. An association between SPS and this affinity towards art and knowledge was found across instruments, especially when focusing on the AES subdomain (NEO: Aesthetics, Ideas, Fantasy, Values, Action; HiPIC: Curiosity, Creativity, Intellect). The AES subdomain comprises items that refer to awareness of art and environmental subtleties, as well as depth of processing (Aron et al., 2012), which refers to processing stimuli more thoroughly (Aron \& Aron, 1997; Patterson \& Newman, 1993). The current results might suggest that the ability to process stimuli more thoroughly is associated with the affinity towards the same, that is, the ability to process aesthetic stimuli on a deeper level is related to the appreciation for it.

\section{Extraversion}

Extraversion might not be a clear-cut correlation candidate for SPS, as across studies associations are either almost non-existent or contributes to a function, which does not explain much variance. Furthermore, Extraversion could be a less straight forward candidate, because of how it is composed. In the FFM, Extraversion covers mostly facets related to positive affect in both the NEO-PI-3 and the HiPIC, such as Excitement-Seeking (NEO-PI-3) or Optimism (HiPIC). In a dimensional approach, introversion would mean the opposite of extraversion, that is, the opposite of positive affect. However, this description of introversion might not be complete. For example, introversion has been shown to be connected to different aspects of deeper processing (for detailed review see Jagiellowicz et al., 2010). In fact, in the 
current studies, we could not see substantial evidence for a clear connection between low extraversion and SPS in young adults, which is in line with Lionetti and colleagues (2019). Interestingly, we also saw some evidence for facets of extraversion being positively connected to the AES aspect of SPS in children and early adolescents, with Shyness as an exception. All in all, Extraversion, as constructed in the FFM of personality, did not seem to be very decisive to characterize all sensitive individuals. It should be studied further if differences between the samples were due to differences in measures, development, or samples.

\section{Agreeableness/Benevolence}

Two facets of Benevolence contributed to the two relevant functions of the young adolescent sample. As stated above, the Emotional Stability domain does not include externalizing behavior. It is instead located in the Benevolence domain in the form of the facet Irritability, which is comparable to the Angry Hostility facet of the Neuroticism domain in the NEO-PI-3. In fact, the two facets contributed strongest to the same thematic function (Function 2 in Young Adult sample; Function 2 in Child and Adolescent sample), although Angry Hostility did not contributed as much as Irritability did.

On the other hand Altruism contributed to the second function of the Child and Adolescent sample, which is an interesting addition to the picture of SPS.

\section{Conscientiousness}

Perseverance contributed secondarily to the first function in the children and young adolescent sample. The analysis showed that easily excitable children who have a low sensory threshold display low perseverance, which might be an early risk factor for developing internalizing behavior. All other facets did not contribute substantially. Both Agreeableness/Benevolence and Conscientiousness seemed to be less directly part of the 
personality profile of SPS. However, these domains may be useful as moderators of associations between this personality profile and outcomes and thus assist in understanding individual differences within the group of highly sensitive individuals. That is, the manifestation and adaptive value of SPS might differ according to one's level of Agreeableness or Conscientiousness.

\section{Sensory Processing Sensitivity}

Across the two studies it became evident that the most important aspects of high sensitivity were ease of excitation and aesthetic sensitivity. LST was less relevant, but consistently contributed to the same function as ease of excitation, indicating that both aspects might not be as distinct, or are not distinguished as well in the items of the instruments. For young adults, on the other hand, LST contributed to explain a small amount of variance in a function that had contributions mainly from Excitement-Seeking, Self-Discipline and Deliberation. For adolescents, LST showed positive correlations to facets of Conscientiousness and Compliance (Benevolence) as well, but the functions explain far too little variance to be informative. It thus might be beneficial to expand and differentiate the LST aspect to obtain more meaningful results.

Across the functions the most important facets for young adults were Aesthetics, Anxiety, Vulnerability, Depression, and Excitement-Seeking. For children and young adolescents the most important facets across functions were Anxiety, Self-Confidence, Optimism and Curiosity.

\section{Summary, Strengths, Limitations, and Future Directions}

The current paper investigated the association between SPS and the FFM of personality at facet levels. To the best of our knowledge, this paper is the first to move beyond the domain level of the FFM and towards a more fine-grained examination of which 
personality facets are specifically relevant for SPS. Our results suggest that SPS can be considered as a blend of specific personality facets across mainly the domains of Neuroticism, Openness (especially in late adolescents and young adults; and on subdomain level, especially when it comes to the AES subdomain) and - to a lesser extent - Extraversion (especially when it comes to the EOE subdomain in both samples and the AES subdomain in children and early adolescents). As such, it might be a distinct construct, that is, it does not overlap with a certain trait completely, but rather made up of particular facets from different personality domains, reflecting a specific personality profile. Comparable profiles have been described earlier, for example, for charismatic personality (Vergauwe, Wille, Hofmans, \& De Fruyt, 2017) and psychopathic personality (e.g., Lynam \& Widiger, 2001; Miller, Lyman, Widiger, \& Leukefeld, 2001), among others. This approach to SPS opens up new ways for both understanding the construct and assessing it (e.g., using FFM-based instruments).

Another important strength of the paper is the inclusion of samples with a broad age range, spanning development from late childhood to early adulthood. Most of the earlier studies recruited only college students as their participants, with small sample sizes in many cases, whereas both of our samples were mostly large community samples, which increases the generalizability of our findings. In addition, we used age appropriate instruments for the two studies, which gave us the opportunity to compare results on a content level: results seem to suggest a personality profile of a highly sensitive person which incorporated internalizing tendencies and appreciation for aesthetics.

In spite of these strengths, some limitations need to be considered as well, especially with respect to the instruments used. All questionnaires relied on self-report, which could have led to self-report biases. Further research has to be conducted to assess inter-rater reliability for the HSP/HSC scale. However, it should be mentioned that it might be difficult for other-raters to assess inner processes, which compose a crucial part of SPS, (John \& 
Robins, 1993). Due to the broad age range across the two studies, different measures of SPS and FFM were used in the two samples. Although both the HSP and the HSC are assumed to measure SPS and both NEO-PI-3 and HiPIC are considered to be measures of FFM domains and facets, the corresponding FFM instruments differ to some extent in content and structure, which hampers comparison of the results across age groups. As a result, it is unclear if differences in findings across both studies reflect true developmental differences versus differences in the content and structure of the instruments. Furthermore, the samples span from older children/young adolescents to young adults, thus it might be advantageous to replicate studies in younger children (maybe with parent report) and older adults. In addition to recruitment at schools, a snowball technique was applied to increase the age range and participant numbers. This could have led to a sampling bias. Furthermore, the samples were collected in Belgium; to generalize the findings to a broader population it might be good to replicate studies in multiple countries across the world.

In addition, no published study before examined associations of the 12-item HSP with FFM facets, which complicates a straightforward comparison of the results of our Study 1 with previous findings. Moreover, although both the HSP and the HSC increasingly become established measures of SPS, it has been suggested that their content validity may still be improved. For example, the aspect of 'depth of information processing' which has been put forward as core characteristic of SPS (Aron \& Aron, 1997) may not fully be captured by the current versions of HSP/HSC (Lionetti et al., 2019) but would be particularly interesting to see its associations to FFM. For instance, it could increase the associations with internalizing tendencies, and facets of Openness/Imagination, but also Deliberation of the Conscientiousness domain could become a more relevant facet. Including deeper processing in the SPS scales might also show differentiating results, depending on mediating effects of Agreeableness and Conscientiousness. 
When using the HSP/HSC to investigate which FFM domains and facets are relevant to the SPS construct, findings will naturally be limited to the aspects of SPS that are sufficiently covered in these instruments. What is more, the strength of associations of FFM domains and facets with SPS as a global construct will in part be due to the representation of SPS aspects in the HSP/HSC (e.g., AES, which emerges as quite distinct from EOE and LST, is represented in a fairly small proportion across the HSP/HSC items). Similarly, although the FFM of personality is generally considered as a comprehensive description of most if not all individual differences in personality (for review see Goldberg, 1993), some facets of personality with direct relevance to SPS may be less represented in the items of specific FFM instruments (e.g., the more sensory aspects of neurotic overload). In addition the HSC scale had a low internal consistency, which might have had consequences for the results of the child sample, as scale scores were used for the canonical correlation analysis. This might have affected a clear cut distinction between the HSC subscales. Thus, findings of the representation of SPS in the FFM should be replicated over and above correlation analyses.

\section{Conclusion}

Overall, we were able to confirm associations between FFM and SPS that were suggested by previous studies, as the most useful facets belonged to Openness to Experience and Neuroticism. However, we also found some evidence for differences in children and adults regarding facets of Extraversion, Agreeableness and Conscientiousness. Thus, by looking at the facet level associations, we were able to gain valuable insight in what drives the domains. It has been shown distinctively that some facets were more important in their association with SPS than others. Aa a result, in order to comprehensively grasp those aspects of personality that characterize highly sensitive individuals, a facet-level analysis is needed. 
The results of both of our studies are promising for understanding SPS within the FFM of personality and the establishment of a SPS personality profile within the FFM. 


\section{Tables}

Table 1

Overview of NEO-PI-3 Facets (Description for High Scorers on the Respective Facet)

\begin{tabular}{|c|c|}
\hline Domains and facets & Description \\
\hline \multicolumn{2}{|l|}{ Emotional Stability } \\
\hline Anxiety & Worry and physiological reactions to anxiety \\
\hline Angry Hostility & Readiness to becoming angry and annoyed, and being temperamental \\
\hline Depression & Self-blame, loneliness, self-confidence/-worth, sadness, and hopelessness \\
\hline Self-Consciousness & Embarrassment and lack of self-worth \\
\hline Impulsiveness & Giving in to cravings and difficulties of restraining and control oneself \\
\hline Vulnerability & $\begin{array}{l}\text { Reduced coping efficacy, difficulties in the decision making process, and } \\
\text { weaker emotional stability. }\end{array}$ \\
\hline \multicolumn{2}{|r|}{ (1) } \\
\hline Warmth & Cordially, approachable, strong bonds with friends \\
\hline Gregariousness & Enjoying crowds and big social gatherings \\
\hline Assertiveness & Dominance, assertiveness and leadership behavior \\
\hline Activity & Lively, fast-paced work and life, vigorous \\
\hline Excitement-seeking & Seeking crowds at big events and scary movies, action and adrenaline chasing \\
\hline Positive Emotions & Positive affect: joyful, cheerful, light-hearted \\
\hline \multicolumn{2}{|l|}{ Openness to } \\
\hline \multicolumn{2}{|l|}{ Experience } \\
\hline Fantasy & Active imagination and an affinity for daydreaming \\
\hline Aesthetics & Enjoying, fascination of, and interest in music and art \\
\hline Feelings & $\begin{array}{l}\text { Experiencing strong emotions, appreciation and recognition of emotions, and } \\
\text { empathy }\end{array}$ \\
\hline Actions & $\begin{array}{l}\text { Trying new methods and ways, and willingness to experience new } \\
\text { surroundings }\end{array}$ \\
\hline Ideas & $\begin{array}{l}\text { Affinity to philosophical and abstract theories, ideas, and discussions, as well } \\
\text { as an eagerness to learn and intellectual interest }\end{array}$ \\
\hline Values & $\begin{array}{l}\text { Tolerance for other societies' idea of right and wrong, and open-mindedness } \\
\text { to different believes }\end{array}$ \\
\hline \multicolumn{2}{|r|}{ (2) } \\
\hline Trust & Trustful, believes in the best of people \\
\hline Straightforwardness & Reluctance to manipulate people and aversion to be called a hypocrite \\
\hline Altruism & Concerns for others \\
\hline Compliance & Cooperation, restraint in negative emotion expression, flexible, level-headed \\
\hline Modesty & $\begin{array}{l}\text { Bottom-up comparison to others, lower opinion of oneself, and the reluctance } \\
\text { to talk about oneself and one's achievements }\end{array}$ \\
\hline Tendermindedness & Social \\
\hline \multicolumn{2}{|l|}{ Conscientiousness } \\
\hline Competence & Self-efficacy and feeling of control over one's life \\
\hline Order & Tidy, organized, neat, demanding \\
\hline Dutiful & Conscientious in performing tasks, dependable, reliable, adhering to principals \\
\hline $\begin{array}{l}\text { Achievement } \\
\text { Striving }\end{array}$ & Working towards goals, drive to get ahead and to excel \\
\hline Self-Discipline & Productive, persevering, even when dealing with a big work load \\
\hline Deliberation & Consideration during decision making and planning processes \\
\hline
\end{tabular}

Note. $(\mathrm{r})=$ reversed item. 
Table 2

Overview of HiPIC Facets (Description for High Scorers on the Respective Facet)

\begin{tabular}{|c|c|}
\hline Domains and facets & Description \\
\hline \multicolumn{2}{|l|}{ Emotional Stability } \\
\hline Anxiety & $\begin{array}{l}\text { Worry, fear and panic, physiological responses to } \\
\text { disappointment, and depressive symptoms }\end{array}$ \\
\hline Self-Confidence & $\begin{array}{l}\text { Having less insecurities, higher opinion of oneself, less self- } \\
\text { doubt, and self-confidence }\end{array}$ \\
\hline \multicolumn{2}{|l|}{ Extraversion } \\
\hline Energy & Energetic, tireless \\
\hline Expressiveness & Shows and expressed feelings, talkative \\
\hline Optimism & Positive affect: joyful, cheerful, light-hearted, careless \\
\hline Shyness & $\begin{array}{l}\text { Difficulties talking to people and making friends, and } \\
\text { uncertainty in social situations }\end{array}$ \\
\hline \multicolumn{2}{|l|}{ Imagination } \\
\hline Creativity & $\begin{array}{l}\text { Imaginative, likes to create and draw, has new and original } \\
\text { ideas }\end{array}$ \\
\hline Intellect & $\begin{array}{l}\text { Quick comprehension and verbal abilities, like a broad } \\
\text { vocabulary }\end{array}$ \\
\hline Curiosity & Willingness to understand how things work and why \\
\hline \multicolumn{2}{|l|}{ Benevolence } \\
\hline Altruism & Sympathetic, caring, helpful \\
\hline Dominance & Authoritarian, will imposing, manipulative, leading \\
\hline Egocentrism & Concern for oneself, jealous, low threshold of feeling hurt \\
\hline Compliance & Polite, reliable, obedient, respects authority \\
\hline Irritability & $\begin{array}{l}\text { Low threshold of being offended and angry, as well as less } \\
\text { ability to self-regulate when feeling angry }\end{array}$ \\
\hline \multicolumn{2}{|l|}{ Conscientiousness } \\
\hline Concentration & Forgetfulness, daydreaming, and getting distracted \\
\hline Perseverance & $\begin{array}{l}\text { Determination to reaching goals and persistence when it gets } \\
\text { hard }\end{array}$ \\
\hline Order & Tidy, conscientious \\
\hline $\begin{array}{l}\text { Achievement } \\
\text { Striving }\end{array}$ & $\begin{array}{l}\text { High achiever, perfectionist, having heavy demands on } \\
\text { oneself, dedicated and hard working }\end{array}$ \\
\hline
\end{tabular}

Note. $(\mathrm{r})=$ reversed item. 
Table 3

Canonical Solution for Neo Personality Facets and High Sensitivity.

\begin{tabular}{|c|c|c|c|c|c|c|c|c|c|c|}
\hline \multirow[b]{2}{*}{ NEO Facets } & \multicolumn{3}{|c|}{ Function 1} & \multicolumn{3}{|c|}{ Function 2} & \multicolumn{3}{|c|}{ Function 3} & \multirow[b]{2}{*}{$\mathrm{h}^{2}$} \\
\hline & $\begin{array}{l}\text { Co } \\
\text { ef }\end{array}$ & $r_{s}$ & $\begin{array}{l}r_{s}^{2} \\
(\%)\end{array}$ & $\begin{array}{c}\text { Coe } \\
f\end{array}$ & $r_{s}$ & $\begin{array}{l}r_{s}^{2} \\
(\%)\end{array}$ & $\begin{array}{c}\text { Coe } \\
f\end{array}$ & $r_{s}$ & $\begin{array}{l}r_{s}^{2} \\
(\%)\end{array}$ & \\
\hline \multicolumn{11}{|l|}{ Neuroticism } \\
\hline Anxiety & $\begin{array}{c}- \\
.16\end{array}$ & $\begin{array}{c}- \\
.17\end{array}$ & .03 & .26 & .79 & .63 & .24 & .14 & .02 & .68 \\
\hline Angry Hostility & $\begin{array}{c}- \\
.15\end{array}$ & $\begin{array}{c}- \\
.03\end{array}$ & $<.01$ & .15 & .44 & .19 & -.05 & .20 & .04 & .23 \\
\hline Depression & $\begin{array}{c}- \\
.13\end{array}$ & $\begin{array}{c}- \\
.02\end{array}$ & $<.01$ & .12 & .71 & .50 & -.09 & .22 & .05 & .55 \\
\hline $\begin{array}{l}\text { Self- } \\
\text { Consciousness }\end{array}$ & .02 & $\begin{array}{c}- \\
.19\end{array}$ & .04 & .07 & .62 & .38 & -.08 & .13 & .02 & .44 \\
\hline Impulsiveness & .03 & .12 & .01 & .01 & .23 & .05 & -.35 & .17 & .03 & .10 \\
\hline Vulnerability & .01 & $\begin{array}{l}- \\
.15\end{array}$ & .02 & .29 & .72 & .51 & .06 & .25 & .06 & .59 \\
\hline \multicolumn{11}{|l|}{ Extraversion } \\
\hline Warmth & $\begin{array}{c}- \\
.01\end{array}$ & .18 & .03 & -.04 & -.14 & .02 & .03 & .06 & $<.01$ & .06 \\
\hline Gregariousness & $\begin{array}{c}- \\
.01\end{array}$ & $\begin{array}{l}- \\
.12\end{array}$ & .01 & -.18 & -.28 & .08 & .03 & .15 & .02 & .11 \\
\hline Assertiveness & .03 & .28 & .08 & -.13 & -.37 & .14 & -.39 &.$\overline{2}$ & .05 & .27 \\
\hline Activity & $\begin{array}{c}- \\
.09\end{array}$ & .06 & $<.01$ & $\begin{array}{l}<- \\
.01\end{array}$ & -.16 & .02 & .08 & .05 & $<.01$ & .03 \\
\hline $\begin{array}{l}\text { Excitement- } \\
\text { seeking }\end{array}$ & .19 & .34 & .11 & -.16 & -.37 & .14 & .57 & .48 & .24 & .49 \\
\hline $\begin{array}{l}\text { Positive } \\
\text { Emotions }\end{array}$ & $\begin{array}{c}- \\
.07\end{array}$ & .12 & .01 & .15 & -.16 & .03 & -.29 & $\begin{array}{c}- \\
.09\end{array}$ & .01 & .05 \\
\hline $\begin{array}{l}\text { Openness to } \\
\text { Experience }\end{array}$ & & & & & & & & & & \\
\hline Fantasy & .24 & .52 & .27 & -.02 & .11 & .01 & .30 & .39 & .15 & .44 \\
\hline Aesthetics & .54 & .75 & .56 & .24 & .45 & .20 & -.26 &.- & .03 & .79 \\
\hline Feelings & .20 & .43 & .19 & .18 & .43 & .19 & -.04 & .03 & $<.01$ & .38 \\
\hline Actions & .15 & .45 & .20 & -.09 & -.38 & .14 & -.11 & .10 & .01 & .35 \\
\hline Ideas & .23 & .65 & .42 & -.05 & .03 & $<.01$ & -.09 & 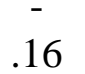 & .03 & .44 \\
\hline $\begin{array}{l}\text { Values } \\
\text { Agreeableness }\end{array}$ & .02 & .45 & .20 & -.04 & .05 & $<.01$ & .25 & .20 & .04 & .24 \\
\hline Trust & $\begin{array}{c}- \\
.03\end{array}$ & .09 & .01 & .01 & -.18 & .03 & $<.01$ &.- & $<.01$ & .04 \\
\hline $\begin{array}{l}\text { Straightforward } \\
\text { ness }\end{array}$ & $\begin{array}{c}- \\
.17\end{array}$ & .20 & .04 & .05 & .22 & .05 & .09 & .05 & $<.01$ & .09 \\
\hline Altruism & .07 & .08 & .01 & -.12 & .06 & $<.01$ & .22 & .06 & $<.01$ & .01 \\
\hline Compliance & $\begin{array}{c}- \\
.15\end{array}$ & $\begin{array}{l}- \\
.15\end{array}$ & .02 & -.04 & -.04 & $<.01$ & -.42 & .23 & .05 & .08 \\
\hline Modesty & $\begin{array}{c}- \\
.01\end{array}$ & $\begin{array}{l}- \\
.13\end{array}$ & .02 & .004 & .25 & .06 & -.14 & .01 & $<.01$ & .08 \\
\hline
\end{tabular}


Tendermindedn

ess

$.04 \quad .18 \quad .03$

$.11 \quad .23$

.05

$-.07 \quad .13 \quad .02$

.10

Conscientiousnes

$\mathrm{s}$

Competence

Order

$$
\begin{array}{ccc}
- & .11 & .01
\end{array}
$$

$\begin{array}{lll}.20 & -.31 \quad .10\end{array}$

$\begin{array}{llll}-.08 & - & .15 & .26\end{array}$

$\begin{array}{lll}.02 \quad- & <6 & <.01\end{array}$

$\begin{array}{lll}.01 \quad .04 & <.01\end{array}$

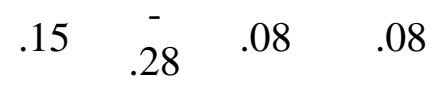

Dutiful

$\begin{array}{lll}.09 & .07 \quad .01\end{array}$

$.01 \quad .03<.01$

$\begin{array}{llll}.22 & - & .06 & .07\end{array}$

Achievement

Striving

$\begin{array}{ccc}- & .02<.01\end{array}$

$\begin{array}{lll}-.03 & -.12 & .01\end{array}$

$\begin{array}{llll}-.25 & - & .15 & .16\end{array}$

Self-Discipline

$\begin{array}{lll}.09 & .07 \quad .01\end{array}$

$\begin{array}{lll}-.17 & -.32 & .10\end{array}$

$\begin{array}{lll}-.17 \quad \overline{4} & .18\end{array}$

.29

Deliberation

$\boldsymbol{R}_{c}^{2}$

.13

$.03<.01$

.10

$10 \quad .12$

$.12 \quad .01$

$\begin{array}{llll}-.46 & \bar{z} & .25 & .26\end{array}$

EOE

$\begin{array}{lll}- & - & \\ .30 & .26 & .07\end{array}$

$\begin{array}{lll}.76 \quad .92 & .85\end{array}$

$.29 \quad .68 \quad .46$

$\begin{array}{ccc}- & - & .01 \\ .19 & .11 & \end{array}$

$\begin{array}{lll}.25 & .41 \quad .17\end{array}$

$.99 \quad \underline{.91} \quad .83$

Note. Structure coefficients $\left(r_{\mathrm{s}}\right)$ greater than $|.45|$ are underlined. Communality coefficients $\left(h^{2}\right)$

$.50 *$

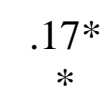

$\begin{array}{llll}.75 & .29 & .08 & \underline{1.0}\end{array}$

$\begin{array}{cccc}- & \overline{\overline{1}} & .53 & \underline{1.0}\end{array}$ greater than $45 \%$ are underlined. Coef $=$ standardized canonical function coefficient; $r_{\mathrm{s}}=$ structure coefficient; $r_{\mathrm{s}}{ }^{2}=$ squared structure coefficient; $h^{2}=$ communality coefficient. $* * p<$ 0.001 . 
Table 4

Canonical Solution for HiPIC Personality Facets and HSC Sensory Processing Sensitivity.

\begin{tabular}{|c|c|c|c|c|c|c|c|c|c|c|}
\hline \multirow[b]{2}{*}{ HiPIC Facets } & \multicolumn{3}{|c|}{ Function 1} & \multicolumn{3}{|c|}{ Function 2} & \multirow[b]{2}{*}{$h^{2}$} & \multicolumn{3}{|c|}{ Function 3} \\
\hline & $\begin{array}{l}\text { Co } \\
\text { ef }\end{array}$ & $r_{s}$ & $\begin{array}{l}r_{s}^{2} \\
(\%)\end{array}$ & $\begin{array}{c}\text { Coe } \\
f\end{array}$ & $r_{s}$ & $\begin{array}{l}r_{s}^{2} \\
(\%)\end{array}$ & & Coef & $r_{s}$ & $\begin{array}{l}r_{s}^{2} \\
(\%)\end{array}$ \\
\hline \multicolumn{11}{|l|}{ Emotional } \\
\hline \multicolumn{11}{|l|}{ Stability } \\
\hline Anxiety & .39 & .88 & .77 & .10 & .06 & $<.01$ & .77 & .03 & .17 & .03 \\
\hline $\begin{array}{l}\text { Self- } \\
\text { Confidence }\end{array}$ & -.26 & $\underline{-.75}$ & .56 & -.14 & .27 & .07 & .64 & .09 & -.07 & .01 \\
\hline \multicolumn{11}{|l|}{ Extraversion } \\
\hline Energy & .03 & -.18 & .03 & .24 & .53 & .28 & .31 & -.20 & -.18 & .03 \\
\hline $\begin{array}{l}\text { Expressivene } \\
\text { Ss }\end{array}$ & .08 & -.04 & $<.01$ & .31 & .64 & .40 & .41 & -.11 & -.17 & .03 \\
\hline Optimism & -.02 & -.40 & .16 & .07 & .59 & .35 & .50 & .04 & -.02 & $<.01$ \\
\hline Shyness & .29 & .66 & .44 & -.18 & $\begin{array}{l}- \\
.37\end{array}$ & .14 & $\underline{.58}$ & .18 & .16 & .03 \\
\hline \multicolumn{11}{|l|}{ Imagination } \\
\hline Creativity & .04 & -.06 & $<.01$ & .21 & .57 & .32 & .32 & .25 & .21 & .05 \\
\hline Intellect & -.16 & -.44 & .20 & .19 & .48 & .23 & .43 & -.30 & .05 & $<.01$ \\
\hline Curiosity & .13 & .02 & $<.01$ & .42 & .69 & .48 & .48 & -.10 & .14 & .02 \\
\hline \multicolumn{11}{|l|}{ Benevolence } \\
\hline Altruism & .12 & .04 & $<.01$ & .02 & .45 & .20 & .20 & .03 & .18 & .03 \\
\hline \multirow{2}{*}{$\begin{array}{l}\text { Dominance } \\
\text { Egocentrism }\end{array}$} & .06 & .03 & $<.01$ & -.03 & .10 & .01 & .01 & -.15 & -.38 & .15 \\
\hline & .14 & .52 & .27 & -.14 & $\begin{array}{c}- \\
.15\end{array}$ & .02 & .30 & .20 & -.24 & .06 \\
\hline \multirow{2}{*}{$\begin{array}{l}\text { Compliance } \\
\text { Irritability }\end{array}$} & .07 & -.19 & .04 & .16 & .30 & .09 & .13 & .38 & .62 & .39 \\
\hline & .01 & .55 & .30 & -.01 & $\begin{array}{c}- \\
.01\end{array}$ & $<.01$ & .30 & .26 & -.14 & .02 \\
\hline
\end{tabular}

Conscientiousne

ss

Concentratio

$\begin{array}{llll}\mathrm{n} & -.05 & -.39 & .15\end{array}$

$-.10 \quad .13$

.02

.17

.33

$.68 \quad .46$

$\begin{array}{llll}-.37 & .04 & <.01 & .26\end{array}$

$.47 \quad .61 \quad .37$

Perseverance $\quad-.23 \quad \underline{-.50} \quad .25$

$.20 \quad .23 \quad .05 \quad .06$

$.06 \quad .63 \quad .40$

Achievement

$.01 \quad-.11 \quad .01$

$.01 \quad .42$

$.18 \quad .19$

.28

.47

.22

$.43 *$

$.23 *$

$.08 *$

$\boldsymbol{R}^{2}$

$*$

$*$

$\underline{.97}$

\begin{tabular}{|c|c|c|c|c|c|c|c|c|c|c|}
\hline EOE & .88 & .98 & .96 & -.27 & $\begin{array}{c}- \\
.08\end{array}$ & .01 & .97 & -.65 & -.18 & .03 \\
\hline ST & .22 & .62 & .39 & .32 & .16 & .03 & .41 & 1.06 & .77 & .59 \\
\hline $\mathrm{ES}$ & .03 & .06 & .00 & .98 & .95 & .90 & .91 & -.23 & -.31 & .09 \\
\hline
\end{tabular}

Note. Function 3 was added for reference, but will not be interpreted. Structure coefficients $\left(r_{\mathrm{s}}\right)$ greater than $|.45|$ are underlined. Communality coefficients $\left(h^{2}\right)$ greater than $45 \%$ are underlined. Coef $=$ standardized canonical function coefficient; $r_{\mathrm{s}}=$ structure coefficient; $r_{\mathrm{s}}^{2}$ $=$ squared structure coefficient; $h^{2}=$ communality coefficient. ${ }^{*} p<0.01 .{ }^{*} p<0.001$. 


\section{References}

Allik, J., Laidra, K., Realo, A., \& Pullmann, H. (2004). Personality development from 12 to 18 years of age: Changes in mean levels and structure of traits. European Journal of Personality, 18(6), 445-462.

Aron, E. N., \& Aron, A. (1997). Sensory-processing sensitivity and its relation to introversion and emotionality. Journal of Personality and Social Psychology, 73(2), 345-368. doi:10.1037/0022-3514.73.2.345

Aron, E. N., \& Aron, A. (2014). De hoogsensitief persoon schaal [The highly sensitive person scale] (P. Bijttebier, S. Weyn, L. Goossens, M. Bastin \& E. Van Hoof, Trans.) [Measurement instrument]. Retrieved from Aron, E. N., \& Aron, A. (1997). Sensoryprocessing sensitivity and its relation to introversion and emotionality. Journal of Personality and Social Psychology, 73(2), 345-368. doi: 10.1037/0022-3514.73.2.345.

Aron, E. N., Aron, A., \& Jagiellowicz, J. (2012). Sensory processing sensitivity: a review in the light of the evolution of biological responsivity. Personality and Social Psychology Review, 16(3), 262-282. doi:10.1177/1088868311434213

Bennett, D. A. (2001). How can I deal with missing data in my study? Australian and New Zealand Journal of Public Health, 25(5), 464-469. doi: 10.1111/j.1467842X.2001.tb00294.x

Boyce, W. T., \& Ellis, B. J. (2005). Biological sensitivity to context: An evolutionarydevelopmental theory of the origins and functions of stress reactivity. Development and psychopathology, 17(2), 271-301. doi:10.1017/s0954579405050145

Cohen, J. (1988). Statistical power analysis for the behavioral sciences (2nd ed.). Hillsdale, NJ: Erlbaum. 
Cohen, J. (1992). A power primer. Psychological Bulletin, 112(1), 155-159. doi:10.1037/0033-2909.112.1.155

Costa, P. T., \& McCrae, R. R. (1992). Revised NEO Personality Inventory (NEO-PI-R) and NEO Five-Factor Inventory (NEO-FFI). Professional manual. Odessa, FL: Psychological Assessment Resources.

De Fruyt, F., Mervielde, I., Hoekstra, H. A., \& Rolland, J.-P. (2000). Assessing Adolescents' Personality with the NEO PI-R. Assessment, 7(4), 329-345. doi:10.1177/107319110000700403

Goldberg, L. R. (1993). The structure of phenotypic personality traits. American Psychologist, 48(1), 26-34. doi: 10.1037//0003-066x.48.12.1303

Greven, C. U., Lionetti, F., Booth, C., Aron, E. N., Fox, E., Schendan, H. E., ... Homberg, J. (2019). Sensory processing sensitivity in the context of environmental sensitivity: A critical review and development of research agenda. Neuroscience \& Biobehavioral Reviews, 98, 287-305. doi:10.1016/j.neubiorev.2019.01.009

Guenther, W.C. (1977). Desk calculation of probabilities for the distribution of the sample correlation coefficient. The American Statistician, 31(1), 45-48.

Hoekstra, H., \& De Fruyt, F. (2014). NEO-PI-3 persoonlijkheidsvragenlijst [NEO-PI-3 personality questionnaire]. Amsterdam, NL: Hogrefe.

Jagiellowicz, J., Xu, X., Aron, A., Aron, E., Cao, G., Feng, T., \& Weng, X. (2010). The trait of sensory processing sensitivity and neural responses to changes in visual scenes. Social Cognitive and Affective Neuroscience, 6(1), 38-47. doi:10.1093/scan/nsq001 
John, O. P. (1990). The "Big Five" (actor taxonomy: Dimensions of personality in the natural language and in questionnaires. In L. A. Pervin (Ed.). Handbook of personality: Theory and research (pp. 66-100). New York: Guilford Press.

John, O. P., \& Robins, R.W. (1993). Determinants of interjudge agreement on personality traits: The Big Five domains, observability, evaluativeness, and the unique perspective of the self. Journal of Personality, 61, 521-551.

Kohnstamm, G. A., Halverson, C. F., Jr., Mervielde, I., \& Havill, V. (Eds.). (1998). Parental description of child personality: Developmental antecedents of the Big Five? Mahwah, NJ: Erlbaum.

Lionetti, F., Aron, A., Aron, E. N., Burns, G. L., Jagiellowicz, J., \& Pluess, M. (2018). Dandelions, tulips and orchids: Evidence for the existence of low-sensitive, mediumsensitive and high-sensitive individuals. Translational Psychiatry, 8(1). doi:10.1038/s41398-017-0090-6

Lionetti, F., Pastore, M., Moscardino, U., Nocentini, A., Pluess, K., \& Pluess, M. (2019). Sensory processing sensitivity and its association with personality traits and affect: A meta-analysis. Journal of Research in Personality, 81, 138-152. doi:10.1016/j.jrp.2019.05.013

Liss, M., Timmel, L., Baxley, K., \& Killingsworth, P. (2005). Sensory processing sensitivity and its relation to parental bonding, anxiety, and depression. Personality and Individual Differences, 39(8), 1429-1439. doi:10.1016/j.paid.2005.05.007

Lynam, D. R., \& Widiger, T. A. (2001). Using the five-factor model to represent the DSM-IV personality disorders: An expert consensus approach. Journal of Abnormal Psychology, 110(3), 401-412. doi:10.1037/0021-843x.110.3.401 
McCrae, R. R., \& Costa, P. T., Jr. (1987). Validation of the five-factor model of personality across instruments and observers. Journal of Personality and Social Psychology, 52(1), 81-90. doi:10.1037/0022-3514.52.1.81

McCrae, R.R., Costa, P. T., Jr., \& Martin, T.A. (2005). The NEO-PI-3: A more readable revised NEO personality inventory. Journal of Personality Assessment, 84(3), 261-70. doi: 10.1207/s15327752jpa8403_05.

Mervielde, I., De Fruyt, F., \& De Clercq, B. (2009). HiPIC: Hiërarchische Persoonlijkheidsvragenlijst voor Kinderen. [HiPIC: Hierarchical personality questionnaire for children]. Amsterdam: Hogrefe.

Miller, J. D., Lyman, D. R., Widiger, T. A., \& Leukefeld, C. (2001). Personality disorders as extreme variants of common personality dimensions: Can the five factor model adequately represent psychopathy? Journal of Personality, 69(2), 253-276. doi:10.1111/1467-6494.00144

Patterson, C. M., \& Newman, J. P. (1993). Reflectivity and learning from aversive events: Toward a psychological mechanism for the syndromes of disinhibition. Psychological Review, 100(4), 716-736. doi:10.1037/0033-295x.100.4.716

Pluess, M. (2015). Individual Differences in Environmental Sensitivity. Child Development Perspectives, 9(3), 138-143. doi:10.1111/cdep.12120

Pluess, M., Assary, E., Lionetti, F., Lester, K. J., Krapohl, E., Aron, E. N., \& Aron, A. (2018). Environmental sensitivity in children: Development of the Highly Sensitive Child Scale and identification of sensitivity groups. Developmental Psychology, 54(1), 5170. doi:10.1037/dev0000406 
Pluess, M., Lionetti, F., Aron, E. N., \& Aron, A. (in preparation). People differ in their sensitivity to the environment: Measurement of sensitivity, association with personality traits and experimental evidence.

Şengül-İnal, G., Kirimer-Aydinli, F. \& Sümer, N. (2018). The role of attachment insecurity and big five traits on sensory processing sensitivity, The Journal of Psychology, 152(7), 497-514. doi:10.1080/00223980.2018.1482255

Sherry, A. \& Henson, R. K. (2005). Conducting and interpreting canonical correlation analysis in personality research: A user-friendly primer. Journal of Personality Assessment, 84(1), 37-48. doi: 10.1207/s15327752jpa8401_09

Smolewska, K. A., McCabe, S. B., \& Woody, E. Z. (2006). A psychometric evaluation of the Highly Sensitive Person scale: The components of sensory-processing sensitivity and their relation to the BIS/BAS and "Big Five." Personality and Individual Differences, 40(6), 1269-1279. doi:10.1016/j.paid.2005.09.022

Vergauwe, J., Wille, B., Hofmans, J., \& De Fruyt, F. (2017). Development of a Five-Factor Model charisma compound and its relations to career outcomes. Journal of Vocational Behavior, 99, 24-39. doi:10.1016/j.jvb.2016.12.005

Weyn, S., Van Leeuwen, K., Pluess, M., Lionetti, F., Greven, C. U., Goossens, L., ... Bijttebier, P. (2019). Psychometric properties of the Highly Sensitive Child scale across developmental stage, gender, and country. Current Psychology. doi:10.1007/s12144-019-00254-5 


\section{Appendix 1}

Highly Sensitive Person Scale - Short Form (12 items; Pluess, Lionetti, Aron, \& Aron, in preparation):

1. Do you seem to be aware of subtleties in your environment?

2. Are you easily overwhelmed by things like bright lights, strong smells, coarse fabrics, or sirens close by?

3. Do you have a rich, complex inner life?

4. Do you get rattled when you have a lot to do in a short amount of time?

5. Are you deeply moved by the arts or music?

6. Are you annoyed when people try to get you to do too many things at once?

7. Do you make a point to avoid violent movies and TV shows?

8. Do you find it unpleasant to have a lot going on at once?

9. Do changes in your life shake you up?

10. Do you notice and enjoy delicate or fine scents, tastes, sounds, works of art?

11. Are you bothered by intense stimuli, like loud noises or chaotic scenes?

12. When you must compete or be observed while performing a task, do you become so nervous or shaky that you do much worse than you would otherwise? 